CONCLUSIONS.

We have now passed in review the conditions present in $\varepsilon$ the more important mucous canals and gland ducts opening in the interior of the body and in one case in the ducts of a gland opening on the skin surface, and a few general observations bearing on the facts so observed may not be out of place. I think from the observations I have described we may consider it proved that by some means or other, and under certain conditions, particles of an insoluble substance, such as indigo, inserted into the orifices of a mucous canal or duct are conveyed along the mucous channel in a reverse direction to that taken by the contents of the tube, or by the secretion or excretion of the glands along such ducts. The conditions which seem to favour this passage are: some interference with the normal flow of the contents of the mucous tube or duct; some arrest or diversion of secretion, such as is produced by a fistulous opening, though it is by no means necessary that this should be complete. By what agency is this transference of foreign particles brought about?

Ciliary action.-Though present in the upper generative tract, cilia are absent in the lower genital tract, in the intestinal canal, in the biliary ducts, in the urinary tract, and in the ducts or glands opening on the skin.

Muscular contraction. - No doubt irregular or reversed peristaltic contractions in the bowel, if present, would bring about the result. It is, however, suggestive that the ascent of the indigo up the colon is not prevented but rather accelerated by the increased downward peristalsis produced by purgatives. Reverse muscular contractions are as yet, moreover, unknown, or rather undemonstrated in the bile ducts, uretbra, and urinary tubes, Fallopian tubes, or in the ducts of glands.

The phenomenon is not due to physical agency alone, such as capillary action. It is absent in the non-living tube. The transterence of particles in empty tubes and ducts is one, and there are other reasons before explained, for regarding: the mucus which coats the walls of the tube or duct as the vehicle in which the particles are carried. Further observations are necessary to ascertain whether a reverse currenta sort of mucous backwater -is present in all mucous channels or whether it only exists where the normal outgoing current of secretion or excretion is interfered with. Such a back current is probably present to a certain extent normally though much increased by any agency, such as a fistula, which starts a flow of mucus from the other end of the canal. The essential conditions, then, seem to be a living tube the walls of which are partially, if not wholly, in apposition and lined by a mucous secretion, while the reversal of this mucous current is favoured by any condition (such as a fistula) which leads to arrest or diversion of the ordinary secretion of the viscus or gland.

The bearing of these remarks on the larger question of infection will be at once apparent. I am inclined to think that in some cases mire attention should be paid to mucous channels as routes of invasion rather than to the lymph or blood stream. Thus I have spoken of the large share which such a mucous, as opposed to a blood, infection plays in the diseases of the female generative tract. The rapid ascent of the urethra by the non-motile gonococcus and the colonisation of deeper portions of the tube, apart from direct extension of growth and in the absence of instrumentation or injection, are thus explained. The ascending infections of the kidney by way of the ureter can also be investigated from this point of view. Our knowledge of the causes which produce biliary and urinary calculi is still very inco nplete. The facts which point to the importance of diseased conditions of the mucous linings of the excretory tubes in favouring the deposition of concretions are of especial importance from this point of view. And bearing in mind the proved transference of particles, under certain conditions, from duodenum to gallbladder and from urethra to ureter, I hope that further light may thus be thrown on these calculous diseases. In fact, the burden of my remarks points to the necessity for the active recognition of the importance of all communications between the efferent canals of the body and the external world and thus accentuates the value of personal hygiene and true cleanliness.

Gentlemen, I hope I have not wearied you with these remarks on what may be called surgical physiology and pathology. As I said at first, instead of pointing to new operations or improvements in surgical technique, instead of giving statistical tables indicating case-mortality after operations, I have tried to turn your attention the other way and to glean a few facts from the many opportunities which modern surgery affords, for the observation of fundamental processes of organic life. And yet, without the surgical revolution which we owe to a few great men and which has been one of the glories of our century, these life-giving operations would have been unperformed and the light which they have shed in many a dark corner of the human body would never have shone. Though the public (the mass of our fellow creatures) are only beginning to grasp, as yet very imperfectly, the allpervading influence which medical and surgical science, and indeed all the sciences which deal with physical and mental efficiency, will assuredly soon exert in the life of the individual, the City, the Nation, and the State; yet it is surely fitting that we medical men, who know these things, should ever recall the services rendered to humanity by the Pasteurs, the Listers, the Kochs, and all those who have done so much to raise our calling to its present proud position-all those who have made these things possible. And how better can we show our gratitude to them than by strenuous individual effort, each of us, in spite of much distraction and scanty opportunity, to add one small fact to the store of garnered knowledge, to bring even one stone to the building of that glorious Temple of Health, the topmost pinnacle of which will only be finished when disease and suffering have been finally vanquished.

\section{TEMPORARY FIXATION OF TESTIS TO THIGH.}

A SERIES OF 25 CASES OPERATED ON FOR UNDESCENDED TESTIS.

By C. B. KEETLEY, F.R.C.S. ENG.

SENIOR SURGEON TO THE WEST LOXDON HOSPITAL.

THE plan of keeping down the testis after operation in this class of cases by fixing it to the thigh was first demonstrated by me in cases shown at the Medical Society of London ${ }^{1}$ on April 16th, 1894. It has been practised and recommended lately by several distinguished surgeons, especially by Professor Rushton Parker ${ }^{2}$ and Professor T. Annandale, ${ }^{3}$ The latter fastens the testicle by a ligature to the skin of the opposite thigh, probably with a view to pull in the line of the inguinal canal. But the pull is quite direct enough from the thigh of the same side and in the latter case the patient himself can easily relax the tension by flexing the hip. Katzenstein of Berlin in the Deutsche II dicinische Wochenschrift, 1902 vol. xxviii., p. 937, described a case in which he fastened the testis to a pedicled flap of skin of the thigh instead of to the fascia lata. I think this is no improvement on my plan. I am indebted for the reference to a very excellent paper on undescended testis by Odiorne and Simmons in the Annals of Surgery for 1904, vol. xl., p. 962. But they bave overlooked my cases published eight years before Katzenstein's I do not believe that any suriteon practically acquainted with my plan would ever afterwards resort to any other. The first step is to free the cord and testis. In many cases this requires the incision of the external oblique used in Bassini's operation for the radical cure of inguinal hernia. There frequently is a congerital inguinal hernia to deal with in these cases and when there is not, incision of the external oblique is sometimes necessary to bring the testicle out of the abdominal cavity and to free it and the cord from deep attachments. It was from Lucas-Championnière's book on hernia published 20 years ago that I learnt the importance of dividing these adbesions and also the comparative ease with which the cord can be separated from the tunica vaginalis high up the inguinal canal.

The main incision $I m * k e$ is over the inguinal canal and the external ring. Two other skin incisions are made in the great majority of cases, one about one and a quarter inches long at the bottom of the sirotum and the other of the same size in the npper and inner part of the thigh adjacent

Transactions of the Merlical Societs, vol. xrii., p. 349; and

THE LAXCF, a pril 21st, 1894, , IC08. a Brit. Med rnit, 1902. vol. ii., p. 1316 
to the scrotal incision. Before cutting the scrotal incision a bed should be made with the finger in the scrotum to receive the testis and the scrotal incision should divide all the structures down to this bed. Something, either a blunt instrument or a piece of gauze, should be passed through this scrotal aperture immediately, or its different layers will cease to be opposite one another. The thigh incision should expose the fascia lata.

FIG 1

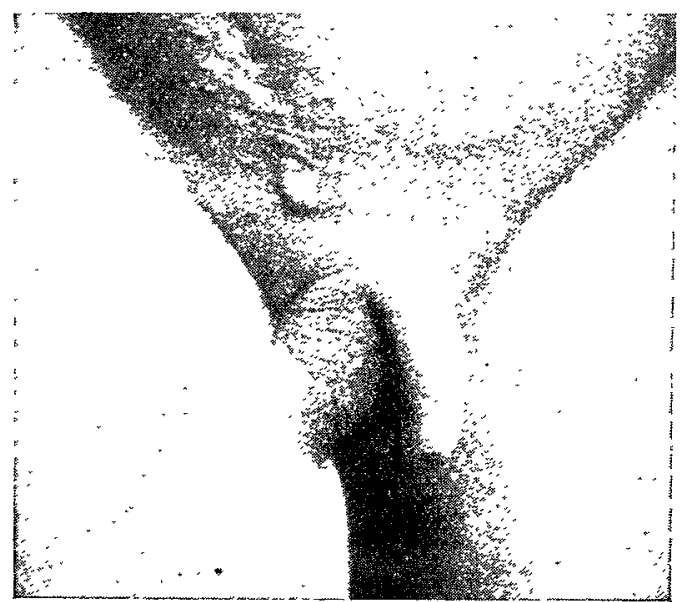

From a young man who har been operated on two years betore tor undescended testis and right inguinal congenital hernia Being pertectly onmertable be did not wish the testis to be separated from the thigh.

The testicle and the cord having been thoroughly freed from everything but the musculo-fibrous bands forming the gubernaculum, which are generally attached to the pillars of the external ring, especially the internal pillar, the gubernaculum is divided as far away as possible from the testicle. A pair of forceps is then passed from below upwards through the hole in the scrotum and the gubernaculum is seized by it and pulled right through the scrotum till it can be seen through the hole in the skin of the scrotum. At the

Fir. 2.

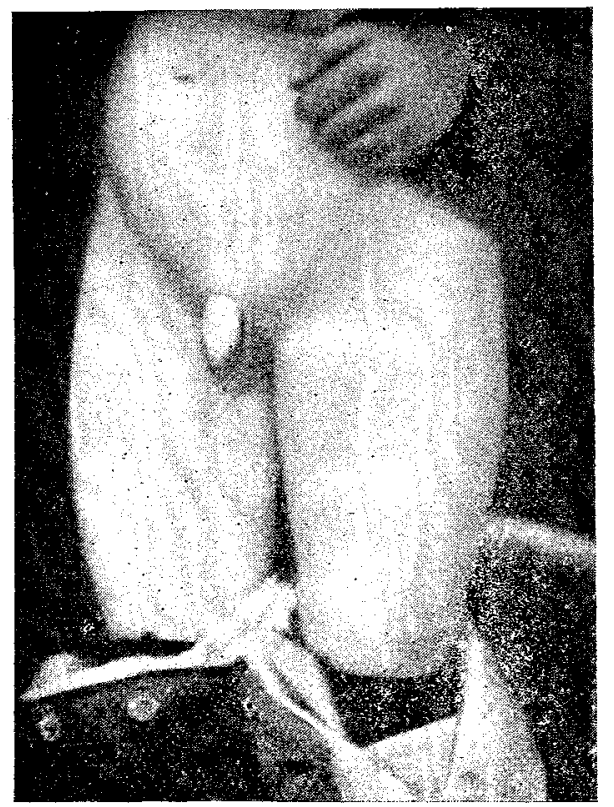

Testis attached to thigh; photograplied just before separation.

game time the tunica vaginalis testis should also be pulled down into the scrotum, though it is not absolutely necessary to keep the testis in its serous bag; indeed, I have often omitted to attend to this point. The posterior borders of the apertures in the skin of the scrotum and thigh are next united by a continuous silkworm-gut suture left long at both ends. Now the gubernaculum testis is sutured with strong catgut to the fascia lata of the thigh; and, lastly, the original silkworm-gut suture is used to complete the union of the skin apertures in the scrotum and thigh to one another. The hernia which is generally present is operated on for radical cure in the way the surgeon thinks best for the individual case. I nearly always do a Bassini's operation, but in very young children have been content with simpler procedures such as that of Kocher.

Even when the testicle has been wholiy intra-abdominal I have always succeeded, not only in bringing it into view chiefly by means of the gubernaculum but also in getting it, by persuasion, to come down to the fascia lata without uncomfortable or painful tension. The thigh can always, if necessary, be brought up to the testis by flexing the hip. The patient is sent to bed with his hip flexed but soon straightens it out himself, thus gradually lengthening a short cord, and I repeat that the process is painless. None of my cases have suffered from any complication except an occasional stitch abscess, due either to delayed dressing or omission to remove the silkworm-gut suture from the skin For dressings is used iodoform gauze wrung out in 1 in 2000 perchloride solution, the gauze being passed behind the scrotum as well as in front, and over the gauze salicylic wool, If the urine wets this dressing no harm is done if it be changed within 24 hours. In older and clean patients it does not generally need to be changed at all until it is time to remove the skin sutures.

I like to leave the testis attached to the thigh for five months. It is rare to find a patient who feels any discomfort from this. One of the above illustrations (Fig. 1) is taken from a patient who had been operated on two years before and who, being perfectly comfortable, saw no reason for having the scrotum freed from the thigh. I have had several such cases. In some of the patients both testes were operated on, sometimes separately, sometimes together.

Occasionally I have attached the fibrous coat of the testis directly to the fascia lata and several times the fibrous fold between the lower end of the epididymis and the body of the testicle. But the gubernaculum is the best. Sometimes 1 have passed the gubernaculum beneath a bridge of fascia lata and then brought its end up again and sewn it to its base. There is an objection to fastening the testis too close to the fascia lata, as then the parts have afterwards to be dissected asunder. In the operation, as I generally do it, they can be separated with a scalpel or sharp pair of scissors, cutting close to the thigh, especially as the testis has a greater tendency to pull the fascia lata up than to be pulled down by the fascia lata. Two or three stitches serve to close the wounds made by the separation, which is effected under local anæsthesia. When I have found no tension at all on the cord and testis I have simply carried the suture fixing the gubernaculum through the bottom of the scrotum with a needle and with the same needle sutured it to the skin of the thigh only, dividing it when removing the skin sutures. But I have only once found the tension so non-existent as to justify this.

The testis generally remains permanently in the scrotum but near its root. 'The fears about a testis just outside the inguinal canal and on the front of the os pubis being dangerously exposed to injury are according to my observation, and I have inquired carefully into this point, imaginary. For example, one of my patients has had his testis in that position for ten years, playing cricket and other games without the slightest inconvenience.

Do these testes grow when brought down in the scrotum? Undoubtedly some of them do, but not to the size of normal testes. Reproductions of photographs are given of two cases (Fjgs. 1 and 2). The scrotum and testicles represented in Hig. 1 had been attached to the thigh two years and the patient was perfectly comfortable, wishing it to be left alone.

Should the undescended testis be brought down by operation? Ordinarily, if an important organ were out of place and could safely be put into correct position, the indication for operating would be regarded as sufficient. Moreover, that indication would be strengthened if there were reason to believe that not only appearance but function would possibly be improved. Now this is true of the testicle. But there is still another reason for bringing down an undescended testis by operation-namely, that in such a case all the most serious and expensive features of the operation may be required to treat the frequently coexisting hernia.

There are some who advise that when an undescended and small testis occurs in connexion with a hernia, then the testis should be removed. They say it is worthless. The burthen of proof of this view lies with them. I think they have 
quite failed to sustain it. Even if it be granted that microscopic examination proves such testicles to be incapable of producing normal spermatozoa-and I doubt if it does, even then, however, the microscopic examination of a testicle just removed from the inguinal canal or from the abdominal cavity does not afford any final proof of what that testis might bave developed into had it been brought down into the scrotum and kept there for several years. Moreover, there has been known to us now for several years still another strong reason for conservatism in dealing with undescended testes-viz., the fact that other glands, such as the thyroid, the suprarenal, and the thymus, exercise a serious influence on the general state of the body in some more or less uncertain way, generally regarded as by producing an internal secriinn.

This last at_ w wnt has of late been unwittingly misrepresented and wcain.ned. It has been put as if it depended on the truth of a quite unproved hypothesis-viz., that which assigns the duty of influencing the general state of the body to certain cells in the testicle of which the function is as yet unknown. This is an interesting surmise, but the argument in favour of preserving as much testicular substance as possible is quite independent of it and must not be regarded as standing or falling with any such speculation. It is quite conceivable that the internal testicular secretion, if there is one, may be a mere by-product of the manufacture of semen.

Lastly, it should always be remembered that each individual has only two testes. And further, sometimes both are undescended. Such cryptorchids are said to have begotten children, though I am not aware whether the evidence in favour of the statement was very severely tested. There are obvious possibilities of error. So far as I know, only one of my patients has married and become a father. But nearly all my patients are still more or less young. Reflecting on the reasons which have brought most of my patients with this affection to consult me, I think they have been one or more of the following: (1) liability to attacks of pain, sometimes very severe, in the inguinal region; (2) the mother's concern at discovering the absence of the missing testis (3) the coexisting rupture; and (4) acute strangulation of a congenital hernia which perhaps had given no sign or warning until the day of strangulation. With regard to No. 1, it may not be possible to tell whether the pain is due to a hernia or to the nipping of the testis as it slips in and out of the canal.

In some of my earlier cases in which I have found no hernia I think I may have overlooked a potential one through not slitting up the inguinal canal. With care an unobliterated process of the tunica vaginalis should usually be found in the inguinal canal. Two, at least, of the cases reported in this paper came under my care while acutely strangulated. One, a young man, was quite unaware that he had a hernia, the other, an old man, had his gubernaculum directed outwards after emerging from the external ring and attached to the front of Poupart's ligament, not far from the anterior superior iliac spine. The 25 cases on which this paper is based were tabulated for me by Dr. W. Trethowan, now of Perth, Western Australia, and by Dr. E. Bell Tawse. They stop short four years ago, since which I have operated on a number of other similar cases. However, as all have fol. lowed practically a similar course ending in a good recovery, it is not necessary to complete and to publish the tables. Analysed they show-

$$
\begin{aligned}
& \begin{array}{lllllll}
\text { Right side affected in } & \ldots & \ldots & \ldots & \ldots & \ldots & 12
\end{array}
\end{aligned}
$$

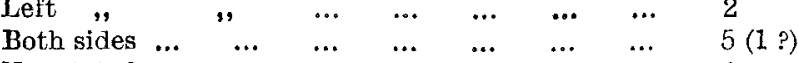

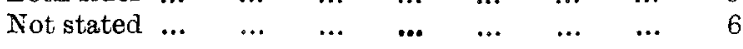

$$
\begin{aligned}
& \begin{array}{llllllll}
\text { Total } & \ldots & \ldots & \ldots & \ldots & \ldots & \ldots & 25
\end{array}
\end{aligned}
$$

The presence of hernia was noted in ten; but a potential hernia-i.e., an unobliterated tunica vaginalis in the inguinal canal-existed in nearly all the rest. In two cases the hernia was strangulated. One hernia (in a man aged 61 years) had a part of the bladder in the inner wall of the sac. In this case already mentioned the testicle had emerged from the inguinal canal and then passed upwards and outwards to be fixed near the anterior superior iliac spine, where there was also a hydrocele. It occurred 17 years ago and I removed the testis. On the earlier cases Macewen's operation for hernia was performed, on most of the later, Bassini's. As regards temperature, in only three is it noted to have risen above $100^{\circ} \mathrm{F}$. after operation, in only one above $101^{\circ}$, and in not a single case did it rise to $102^{\circ}$. In the great majority the highest point was $99^{\circ}$ to $99 \cdot 6^{\circ}$. In seven cases the charts are missing."

Grosvenor-street, $\mathbf{W}$

\section{ON THE TREATMENT OF ACUTE SUMMER DIARRHCEA IN INFANTS.}

By J. A. COUTTS, M.B. CaNTAB., F.R.C.P. Lond.,

PHYSICTAN TO THE EAST LOADON HOSPITAL FOR CHILDREN.

THE theme of acute infantile summer diarrhca is a somewhat dispiriting one, nor is the depression so commonly associated with recollections of it at all relieved by a sense of any conspicuous success in its treatment. It is, nevertheless, an important complaint both from its extreme prevalence and for the large share attributable to it in our excessive infantile mortality.

Any form of diarrheea my occur in infants during summer weather but the particular one I am dealing with is only too readily recognisable without any further specifying or description. Occurring in widespread epidemics when the weather is unduly warm it floods the out-patient department and the wards of every children's hospital and its treat. ment exacts the major part of the time and attention of both the resident and the visiting staffs. The complaint is known under various names, the two commonest, perhaps, being cholera infantum and acute gastro-enteritis. To both such names, however, there are objections, in that the one implies a connexion with another totally different and distinct disease and the other assumes a pathological condition of the stomach and intestines which is seldom, if ever, verified on post-mortem examination. The symptoms are apt to prove monotonous in their unvarying sameness, being mainly comprised in sudden onset, with vomiting and diarrhœe, speedily followed by profound collapse. One feature, however, distinguishes the complaint from all others ordinarily occurring in these climes and this is the rapidity with which the tissues are drained of their fluids and thereby a healthy infant is reduced in a very few hours to a wasted one with wrinkled skin, depressed fontanelle, sunken eyes, cold breath, and almost inaudible cry.

As an instance of the completeness of this tissue drainage, I may quote a remarkable case that occurred many years ago in the practice of my colleague, Dr. Eustace simith. This case was that of an infant with chronic hydrocephalus, who was admitted into the Shadwell Hospital with acute summer diarrhœe. In the course of the last complaint the cerebral ventricles became drained of their distending fluid, with the result that both brain and vault of the skull collapsed upon their bases and, with the infant in a vertical position, half a pint or more of water could have been poured into the concavity produced in the skull and there retained. Oddly enough, doubtlessly owing to the integrity of the more strictly vital centres in the medulla, the infant lived for several days in this condition, and at the post-mortem examination the only remains of the brain were a shapeless disintegrated pulp on the floor of the skull. The severity of the drainage of the tissues and the importance of this element in the complaint may be readily gauged when even the cerebral ventricles can be emptied of their normal fluid.

Another point in the disorder may be briefly touched upon from its extreme importance in prognosis and this is the presence or absence of pyrexia. In every case probably the temperature is raised at the start and sinks below the normal in the condition of collapse. Recovery from the last is usually accompanied by a temporary rise of temperature above the normal. Cases where this rise persists and cases where the temperature remains high without the occurrence of collapse are of infinitely graver prognosis than those in which the temperature is normal. It has been pointed out that the heightened temperature may persist when both diarrhcea and vomiting have practically ceased, showing the toxæmic nature of the complaint. In my opinion too little stress has been laid upon this question of pyrexia, and given

4 Three patients operated on were shown at the Medical Society of London on Jan. 26th, 1903. In one of them, operated on nine years before, the testicle had certainly grown. It had the testicular sensation markedly. (Transactions of the Medical Society of London, vol. xxvi., p. 332 .) 